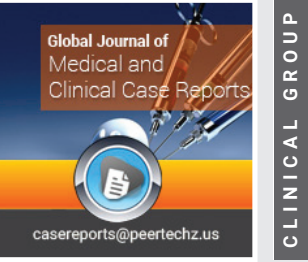

\title{
An unusual case of foreign body aspiration
}

\author{
Vanitha Palanisamy ${ }^{1 *}$, Sia Kian Joo ${ }^{1}$, Chong Aun Wee ${ }^{1}$, \\ Mohd Afiq mohd Amin², Shahrul Amry Hashim ${ }^{2}$ and $\mathrm{Ng}$ \\ Syiao $\mathrm{Wei}^{3}$
}

Received: 05 August, 2019

Accepted: 27 July, 2021

Published: 28 July, 2021

*Corresponding author: Vanitha Palanisamy, Department of Otorhinolaryngology, University of Malaya Medical Centre, Kuala Lumpur, Malaysia, E-mail: nitas23@yahoo.com

Keywords: Foreign body aspiration; Voice prosthesis; Laryngectomy

https://www.peertechzpublications.com

\section{Check for updates}

'Department of Otorhinolaryngology, University of Malaya Medical Centre, Kuala Lumpur, Malaysia

${ }^{2}$ Department of Surgery, University of Malaya Medical Centre, Kuala Lumpur, Malaysia

${ }^{3}$ Department of Otorhinolaryngology, Hospital Sultanah Aminah, Johor Bahru, Johor, Malaysia

\begin{abstract}
Tracheo-Oesophageal Puncture (TEP) with voice prosthesis insertion is considered as a gold standard among various voice rehabilitation procedures in laryngectomized patients. It is easily reversible with a high success rate, and the speech, which closely resembles laryngeal speech, develops faster than esophageal speech. However the prosthesis has to be cleaned regularly to ensure proper function as well as longevity of the voice prosthesis valve system. There are not many incidents of the voice prosthesis cleaning brush reported, as the cleaning brush is made to be durable and able to withstand repetitive usage. Hereby we describe an unusual case of a laryngectomized patient who had aspirated a broken tip of a cleaning brush while cleaning his voice prosthesis. The delay in removal of the aspirated foreign body due to technical difficulty had led to lung collapse subjecting the patient to partial lobectomy. We would like to highlight several aspects in this case report, firstly patients should be counselled regarding the proper techniques to clean the voice prosthesis and they should be vigilant during the cleaning process to prevent aspiration in case of accidental broken of cleaning brush. Secondly the incident should be reported to the manufacturer so that the durability of the cleaning brush is reviewed and improvised. Lastly, prompt management of foreign body aspiration should be implied to prevent complications.
\end{abstract}

\section{Introduction}

Tracheo-Oesophageal Puncture (TEP) with voice prosthesis insertion is considered as a gold standard among various voice rehabilitation procedures in laryngectomized patients [1,2]. It was first introduced by Bloom and Singer in 1979 [3] and remained popular as it is easily reversible with a high success rate, and the speech, which closely resembles laryngeal speech, develops faster than esophageal speech. However the prosthesis has to be cleaned regularly to ensure proper function as well as lasting the longest lifetime of the valve. The patients will be trained by the provider on the methods of cleaning by using the voice prosthesis cleaning brush and flush.

However the prosthesis insertion is associated with complications. The most common problem encountered is the leakage of fluids through the prosthesis [4] which is frequently due to fungal colonization of the valve system or a poorly fitting valve. There are not many incidents of the voice prosthesis cleaning brush reported, as the cleaning brush is made to be durable and able to withstand repetitive usage. Hereby we describe an unusual case of a laryngectomized patient who had aspirated a broken tip of a cleaning brush while cleaning his voice prosthesis.

\section{Case report}

A 60 years old man with history of laryngeal cancer was brought to the Emergency Department of University Malaya Medical Centre (UMMC) after he accidentally aspirated a broken voice prosthesis cleaning brush. He was diagnosed with laryngeal cancer and underwent total laryngectomy in 2011. This was followed by 5 cycles of chemotherapy and 37 fractions of radiotherapy. The patient underwent a secondary Tracheo Esophageal Puncture (TEP) in 2014 for voice rehabilitation. He was given adequate training on the care of the voice prosthesis using the cleaning brush.

On the day of incident, the patient was routinely cleaning the prosthesis using the cleaning brush. During cleaning, the tip of the brush broke and slipped into the airway via the neck stoma. He tried coughing it out but was unable to retrieve the foreign body. The patient was rushed to the emergency 
department. At presentation the patient had mild shortness of breath and cough, but did not exhibit signs of respiratory distress. His vital signs are otherwise stable. Upon reviewing the $\mathrm{X}$-ray, the attending medical officer noted foreign body at the left bronchus. The patient was referred to Otorhinolaryngology team Figure 1.

A bedside flexible fiberoptic scope was carried out by the Otorhinolaryngology team via the neck stoma however the foreign body was not visualised but there were secretions at the left bronchus. Respiratory team had attempted foreign body removal twice using flexible bronchoscopy under sedation but unsuccessful. Subsequently, the patient was referred to the cardiothoracic team for further management. However the patient deteriorated and developed fever, worsening cough and breathing difficulty. A High Resolution Computer Tomography (HRCT) of thorax was ordered and showed a foreign body in the left segmental bronchiole causing left posterobasal segmental collapse. Patient was subjected to Video-Assisted Thoracoscopic Surgery (VATS) for foreign body removal under Cardiothoracic Surgery (CTS) team. Intraoperatively, a cluster of lymph nodes was noted at left hilar region. Due to difficulty in mobilising the pulmonary artery, a mini thoracotomy with left lower lung lobectomy was performed to retrieve the foreign body. Post operative period the patient recovered well. He was discharged after completing antibiotics.

\section{Discussion}

Foreign body aspiration is more commonly seen in children than in adults, and it is the commonest cause of accidental death in children [5-9]. Laryngectomized patients are more susceptible of foreign body aspiration due to easy accessibility of the stoma opening at the anterior neck. Usually the stoma is covered by a humidifier or small towel to prevent the entry of dust or other foreign materials into the airway. There have been a few reports of laryngectomees inhaling foreign bodies, especially the voice prosthesis $[10,11]$.

The modern method of voice rehabilitation includes insertion of tracheoesophageal prosthesis, a one-way valve voice prosthesis between the trachea and esophagus [12]. By occluding the stoma digitally, the air from the lung passes through the valve and enters into the esophagus causing vibration of the esophageal wall to produce voice. It allows the laryngectomized patients to vocalise immediately after its

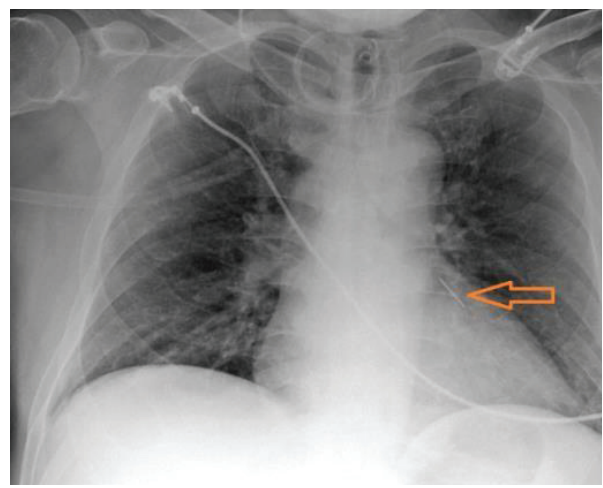

Figure 1: Chest X-Ray showing foreign body at left main bronchus. insertion. However the procedure carries some complications. The early complications include bleeding, infection leading to mediastinitis and abscess, esophageal perforation and fluid leakage around prosthesis. The late complications include fluid leakage, formation of granuloma around the prosthesis, dislocation or aspiration of the prosthesis, tracheostomal stenosis and fungal infection [13]. It is very important to maintain the hygiene of voice prosthesis to ensure its optimal function and durability, otherwise the ability to speak can be compromised. It is recommended that the voice prosthesis is cleaned at least twice a day (morning and evening), preferably after food intake, as the food and mucus are commonly trapped. A voice prosthesis cleaning brush rarely becomes the object of aspiration due to its size and durability. However the tip of the brush may break off after repetitive usage. Hence it is important to alert patients to be vigilant while cleaning the voice prosthesis to prevent aspiration of foreign bodies. In cases of aspirated broken cleaning brush, the incidents should be reported to the manufacturer so that the durability of the cleaning brush is reviewed and improvised.

Various clinical pictures and outcomes of foreign body inhalation in adults have been described in previous literature. The clinical presentations of foreign body inhalation in adults may be insidious and could be overlooked for many years. This may lead to diagnosis challenges to the surgeons due to variable clinical manifestations [11,14]. Hence immediate medical attention is needed to prevent complications such as asphyxiation, post-obstructive pneumonia, haemoptysis, foreign body granuloma, bronchiectasis, atelectasis and chronic cough [11]. In cases suspicious of foreign body aspiration, chest radiograph should be ordered. It could be normal or may demonstrate air trapping, an impacted foreign body, or atelectasis during the early presentation. In the event of failure in locating the foreign body through flexible fiberoptic scope or chest radiography, a HRCT thorax should be done to detect radiolucent foreign body and identify parenchymal changes in the tracheobronchial tree.

Rigid bronchoscopy has been the gold standard for the removal of tracheobronchial foreign body for many years, especially so in children [11]. However, recent improvements in techniques and equipment for flexible fibreoptic bronchoscopy has made it a valuable tool for foreign body removal in adults, especially the laryngectomee. The location of the stoma and most often rigid neck due to radiation therapy made it impossible to use rigid bronchoscopy for foreign body removal in these patients. Lan et al demonstrated that flexible bronchoscopy was safe and useful in tracheobronchial foreign retrieval, especially in cases which foreign bodies are impacted too distally for the rigid bronchoscopy [15]. Besides, flexible bronchoscopy is more suitable in mechanically ventilated patients or patients with cervical instability where rigid bronchoscope insertion is difficult. In comparison with rigid bronchoscopy which requires general anaesthesia, flexible bronchoscopy can be done under intravenous sedation. Complications are minimal with either rigid or flexible bronchoscopy. Limper and Prakash reported an overall rate of $5 \%$ [16], mild bleeding was the main complication and abated spontaneously in all cases. It is important to remove the foreign body to prevent complications, 
morbidities and prolonged hospitalisation. In our patient, the delay in foreign body retrieval due to technical difficulty had led to lung collapse to which partial lobectomy had to be done. Such treatment for the condition is rare.

\section{Conclusion}

It is important to teach the laryngectomised patients the correct techniques to clean the valve system to ensure the proper functioning and longevity of the voice prosthesis. They should remain vigilant while cleaning to reduce the risk of aspiration. Sudden onset of respiratory distress in laryngectomized patients should immediately raise suspicion of possible foreign body aspiration. Prompt history and examination is needed to prevent patients from further deterioration. Careful examination of the stoma, lung auscultation and bedside flexible scope are needed to look for foreign body and degree of airway obstruction caused by the foreign body. If examination findings are negative, a chest X-Ray is ordered to confirm the diagnosis. Once identified, the foreign body needs to be removed as soon as possible to reduce complications. Failure in identifying the foreign body warrants a CT scan to locate the foreign material. Cases of aspirated broken cleaning brush should be reported to the manufacturer so that the quality of the cleaning brush is reviewed and thus to be improvised Figures 2-4.

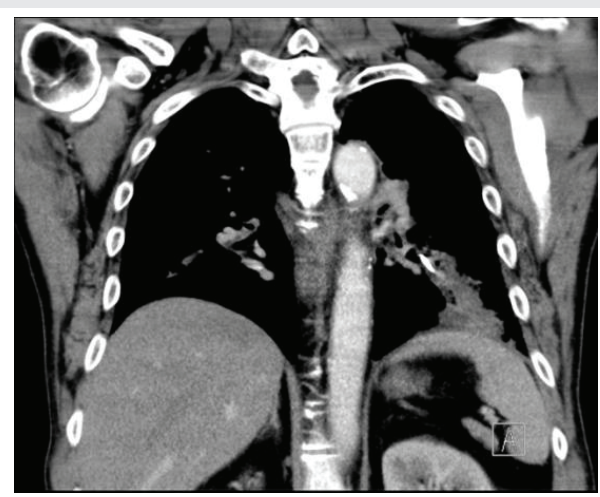

Figure 2: HRCT Thorax Coronal View showing foreign body at left segmenta Figure 2:
bronchiole.

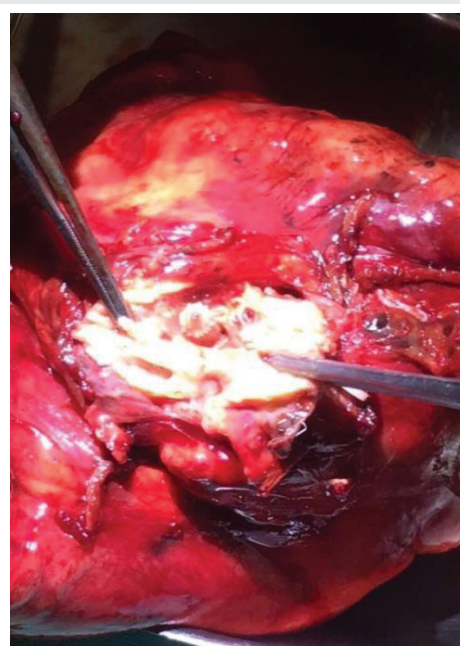

Figure 3: Foreign body in the left lower lung lobe.

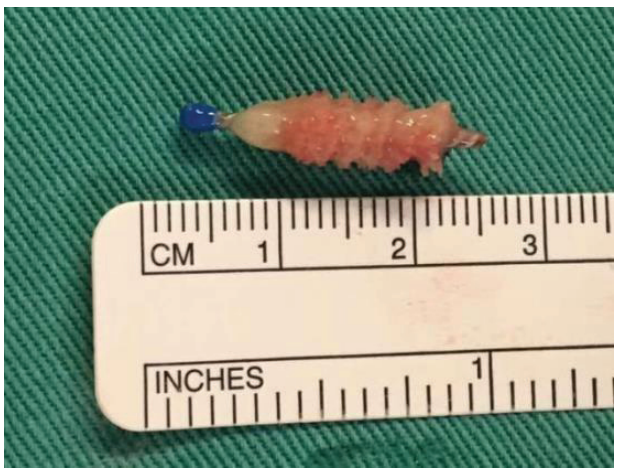

Figure 4: Foreign body.

\section{References}

1. Bozec A, Poissonnet G, Chamorey E, Demard F, Santini J, et al. (2010) Results of vocal rehabilitation using tracheoesophageal voice prosthesis after total laryngectomy and their predictive factors. Eur Arch Otorhinolaryngol 267 751-758. Link: https://bit.ly/2WtQAnr

2. Hotz MA, Baumann A, Schaller I, Zbären P (2002) Success and Predictability of Provox Prosthesis Voice Rehabilitation. Arch Otolaryngol Neck Surg 128 687-691. Link: https://bit.ly/2UZhBPd

3. Singer MI, Blom ED (1980) An Endoscopic Technique for Restoration of Voice after Laryngectomy. Ann Otol Rhinol Laryngol 89: 529-533. Link: https://bit.ly/3f2Tq9g

4. Kazi R, Rhys-Evans P, Harrington K, Dwivedi CR (2012) Issues in Head and Neck Cancer. 1st ed. Byword Books Private Limited.

5. Banerjee A, Rao KS, Khanna SK, Narayanant PS, Gupta BK, et al. (1988) Laryngo-tracheo-bronchial foreign bodies in children. J Laryngol Otol 102 1029-1032. Link: https://bit.ly/3I5KyDS

6. Kramer TA, Riding KH, Salkeld LJ (1986) Tracheobronchial and esophagea foreign bodies in the pediatric population. J Otolaryngol 15: 355-358. Link: https://bit.ly/3BODG3n

7. Mantel K Butenandt I (1986) Tracheobronchial foreign body aspiration in childhood: A report on 224 cases. Eur J Pediatr 145: 211-216. Link: https://bit.ly/3yfqfHG

8. Mani N, Soma M, Massey S, Albert D, Bailey CM (2009) Removal of inhaled foreign bodies-Middle of the night or the next morning? Int $\mathrm{J}$ Pediatr Otorhinolaryngol 73: 1085-1059. Link: https://bit.ly/2WvjmnG

9. Kishore A, Roy D (2001) Inhaled foreign bodies in laryngectomees. Indian $J$ Otolaryngol Head Neck Surg 53: 315-317. Link: https://bit.ly/3zOixVt

10. Conte SC, De Nardi E, Conte F, Nardini S (2012) Aspiration of tracheoesophagea prosthesis in a laryngectomized patient. Multidiscip Respir Med 7: 25. Link: https://bit.ly/3BKTEMd

11. Loo CM, Hsu AA, Eng P, Ong YY (1998) Case Series of Bronchoscopic Removal of Tracheobronchial Foreign Body in Six Adults. Ann Acad Med Singap 27: 849-853. Link: https://bit.ly/3zKuT0Q

12. Pawar P, Sayed S, Kazi R, Jagade MV (2008) Current status and future prospects in prosthetic voice rehabilitation following laryngectomy. J Cancer Res Ther 4: 186-191. Link: https://bit.ly/3748fnw

13. Yenigun A, Eren SB, Ozkul MH, Tugrul S, Meric A (2015) Factors influencing the longevity and replacement frequency of Provox voice prostheses. Singapore Med J 56: 632-636. Link: https://bit.ly/3I5Lnws

14. Wolkove N, Kreisman H, Cohen C, Frank H (1982) Occult foreign-body aspiration in adults. JAMA 248: 1350-1352. Link: https://bit.ly/3rCahVE 
15. Lan RS, Lee CH, Chiang YC, Wang WJ (1989) Use of Fiberoptic Bronchoscopy to Retrieve Bronchial Foreign Bodies in Adults. Am Rev Respir Dis 140: 17341347. Link: https://bit.ly/374UwNt
16. Limper AH, Prakash UB (1990) Tracheobronchial Foreign Bodies in Adults Ann Intern Med 112: 604-609. Link: https://bit.ly/2WyHGoR
Discover a bigger Impact and Visibility of your article publication with

\section{Peertechz Publications}

\section{Highlights}

- Signatory publisher of ORCID

* Signatory Publisher of DORA (San Francisco Declaration on Research Assessment)

* Articles archived in worlds' renowned service providers such as Portico, CNKI, AGRIS, TDNet, Base (Bielefeld University Library), CrossRef, Scilit, J-Gate etc.

* Journals indexed in ICMJE, SHERPA/ROMEO, Google Scholar etc.

- OAI-PMH (Open Archives Initiative Protocol for Metadata Harvesting)

* Dedicated Editorial Board for every journal

* Accurate and rapid peer-review process

* Increased citations of published articles through promotions

- Reduced timeline for article publication

Submit your articles and experience a new surge in publication services (https://www.peertechz.com/submission).

Peertechz journals wishes everlasting success in your every endeavours.

Copyright: @ 2021 Palanisamy V, et al. This is an open-access article distributed under the terms of the Creative Commons Attribution License, which permits unrestricted use, distribution, and reproduction in any medium, provided the original author and source are credited.

Citation: Palanisamy V, Joo SK, Wee CA, Mohd Amin MA, Hashim SA, et al. (2021) An unusual case of foreign body aspiration. Glob J Medical Clin Case Rep 8(2): 072-075. DOI: https://dx.doi.org/10.17352/2455-5282.000133 